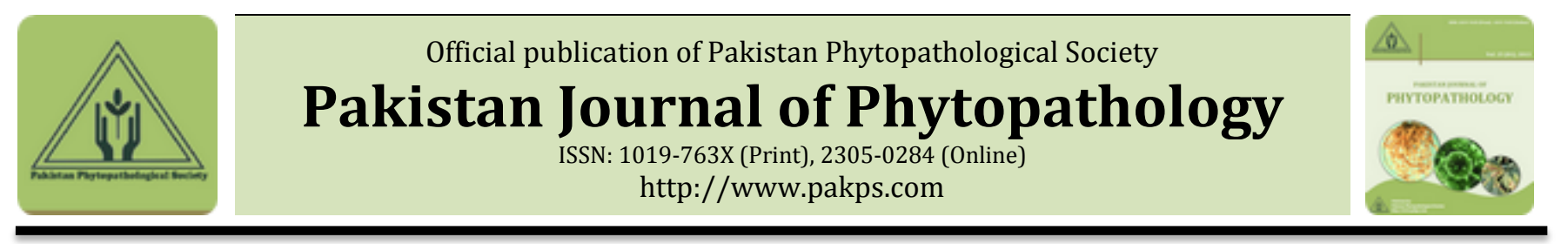

\title{
POLYALTHIA LONGIFOLIA A NEW HOST RECORD OF NIGROSPORA SPHAERICA CAUSING LEAF BLIGHT IN PAKISTAN AND EFFICACY DETERMINATION OF VARIOUS FUNGICIDES AGAINST THIS PATHOGEN
}

\author{
aImran Ul. Haq*, a Muhammad Shoaib, bSiddra Ijaz, cKhalid P. Akhtar, aSajid A. Khan and aNabeeha A. Khan \\ a Department of Plant Pathology, University of Agriculture, Faisalabad- Pakistan. \\ ${ }^{b} C A B B / U S P C A S$ AFS, University of Agriculture, Faisalabad- Pakistan. \\ ${ }^{c}$ Nuclear Institute for Agriculture and Biology, Faisalabad-Pakistan.
}

\section{A B S T R A C T}

Severe leaf and stem necrosis of Polyalthia longifolia (Ulta-Ashoka) was observed in Pakistan during summer 2012. Symptoms on leaves were initiated with drying followed by whole leaf and plant drying. The casual pathogen was identified as Nigrospora sphaerica based on cultural characteristics and conidial morphology. Its pathogenicity was proven on healthy P. longifolia plants. This is the first report of Nigrospora sphaerica causing leaf blight on P. longifolia in Pakistan. Furthermore, for the selection of most effective fungicide that can be used for the chemical management of the disease under field conditions three fungicides viz., Antracol (ChlorotHalonil), Halonil (Propineb) and Aerosil (Thiophenate methyl) were evaluated against mycelia growth of Nigrospora sphaerica under controlled conditions. Two concentrations were used for every fungicide as it was 500 and $1000 \mathrm{ppm}$. It was concluded from the results obtained that Halonil was found to be effective fungicide by reducing the mycelia growth of Nigrospora sphaerica by 78.4\%. followed by Antracol and Aerosol respectively.

Keywords: Nigrospora sphaerica, Ulta-Ashoka, ornamental plant, first disease report and fungicides.

\section{INTRODUCTION}

Polyalthia longifolia (also known as mast tree, cemetery tree, Ulta Ashoka) is a tall, ornamental and evergreen tree (Mitra, 1993; Warrier et al., 2002). The genus of $P$. longifolia comprises of about 120 species and belongs to family Annonaceae (Mitra. 1993). Polyalthia longifolia is cultivated widely throughout tropical and subtropical asia as an ornamental and has use as an anthelmintic, germicide, and as a folk medicine for the treatment of pyrexia. Previous studies on its leaves, bark, roots, root bark, and seeds have revealed that various types of diterpenoids and alkaloids are present which plays important role in numerous biological activities such as anti-inflammatory, antihypertensive, antimicrobial and cytotoxic effects (Chen et al., 2000). Its bark has medicinal properties to cure fever, skin diseases, diabetes, hypertension, helminthiasis and vitiated

* Corresponding Author:

Email: imran_1614@yahoo.com

(c) 2017 Pak. J. Phytopathol. All rights reserved. conditions of vata and pitta (Warrier et al., 2002). The fungicidal effect of $P$. longifolia has also been reported by many workers (Nair et al., 2007). In May 2012, P. longifolia plants growing in avenue and in landscape areas of University of Agriculture, Faisalabad- Pakistan, along roads and ornamentals plant nurseries of district Faisalabad, Pakistan were found to be heavily affected by leaf blight disease. (Haq et al., 2014) Initial symptoms on leaves started with drying of leaves from margins Severely infected leaves turn purple or reddish color, giving the leave an overall purple cast followed by complete leaf necrosis on whole plant, resulting in severe defoliation. Under severe infections branches become dried and occasionally cause plant death (Figure 1\&2). The samples were collected from different localities of University of Agriculture, Faisalabad. Isolation of the causal fungus was made from diseased tissue. On isolation, different conidia that were black, single celled, globose $(14-18 \mu \mathrm{m})$, borne on a hyaline vesicle at the tip of the conidiophore were obtained and 
these characteristics were matched with the characteristics of Nigrospora sphaerica and hence it was identified as conidia of Nigrospora sphaerica on the basis of these morphological characteristics (Figure 3). To confirm and fulfil the Koch's postulates, the pathogenicity test was conducted and N. sphaerica was re isolated from infected leaves. Furthermore for the

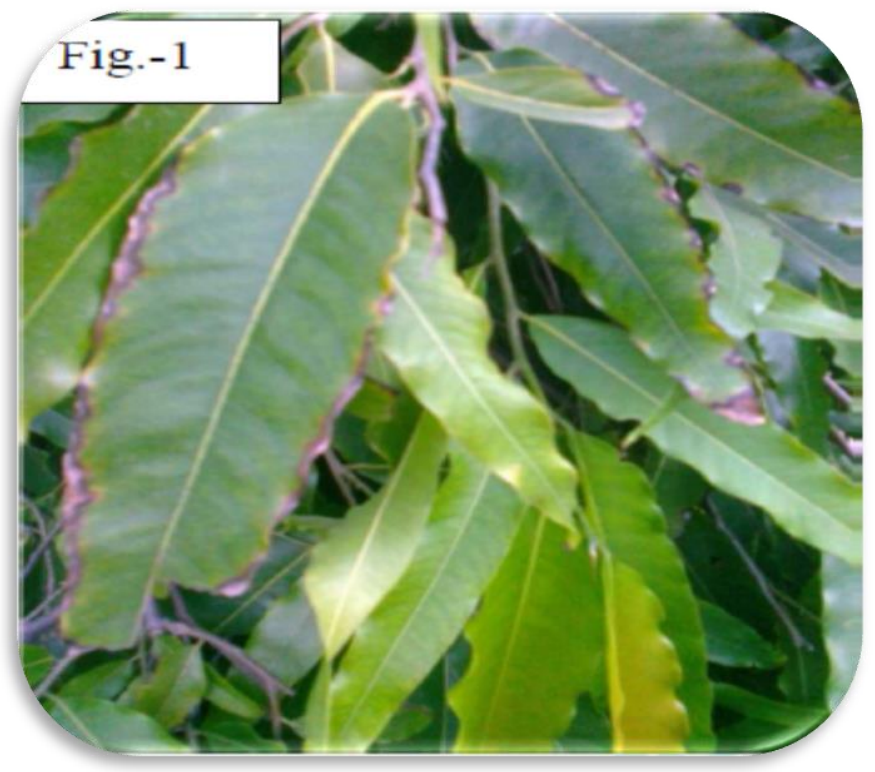

Figure 1. P. longifolia leaves representing drying of margin

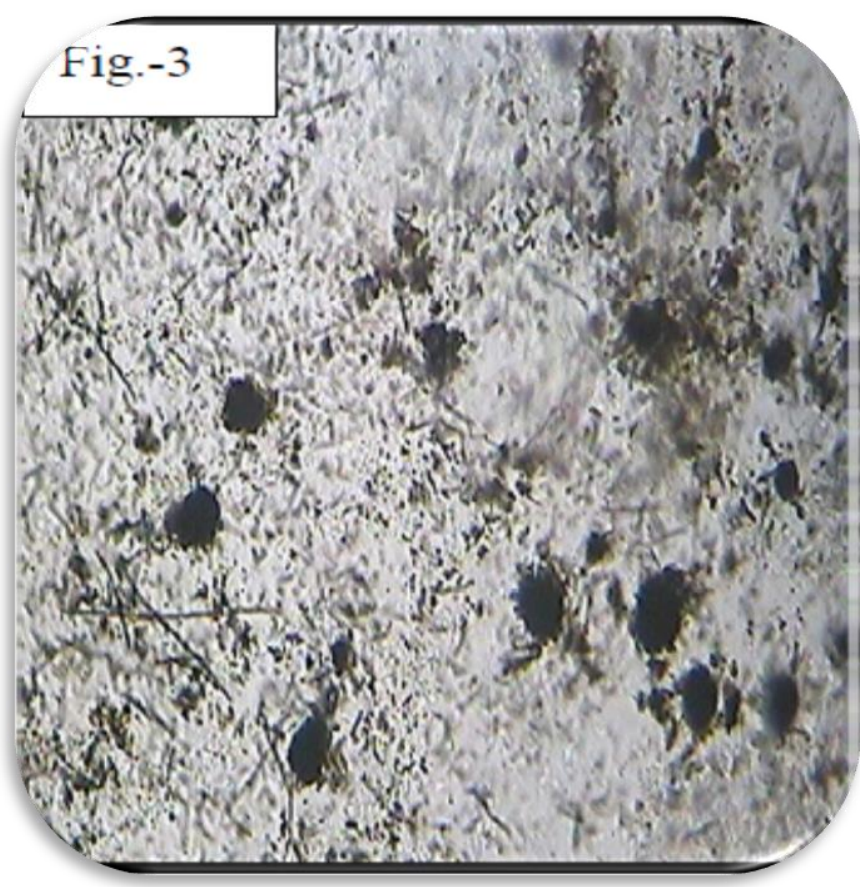

Figure 3. Spores of N. sphaerica selection of most effective fungicide that can be used for the chemical management of the disease under field conditions three fungicides viz.,Antracol (ChlorotHalonil),Halonil (Propineb) and Aerosil (Thiophenate methyl) were evaluated against mycelia growth of Nigrospora sphaerica under controlled conditions.

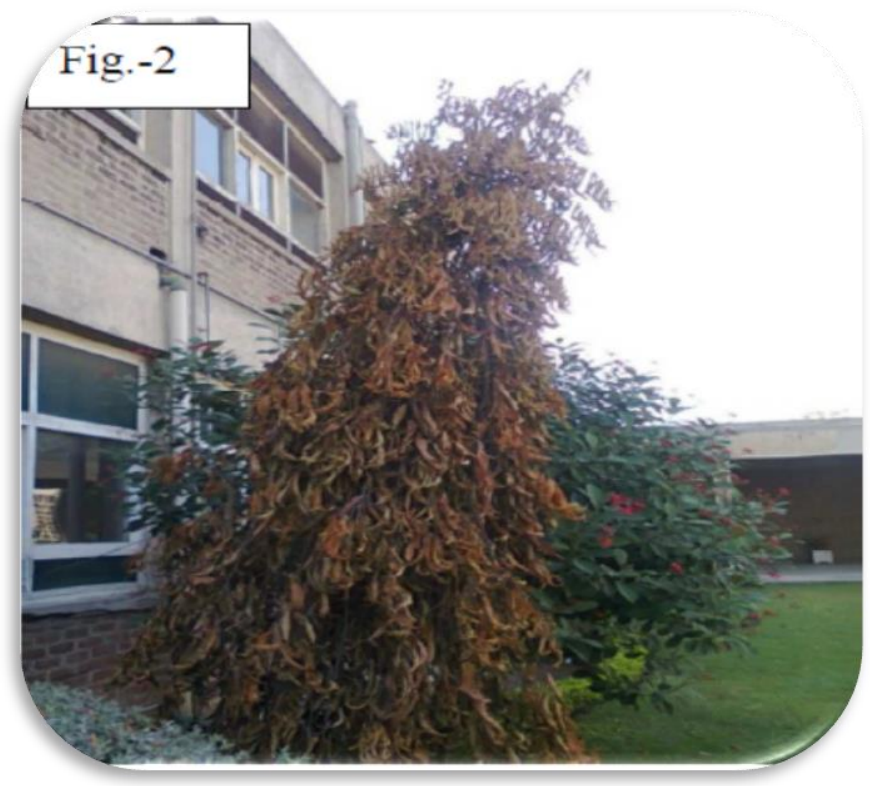

Figure 2. Naturally infected plants $P$. longifolia showing necrosis on whole plant

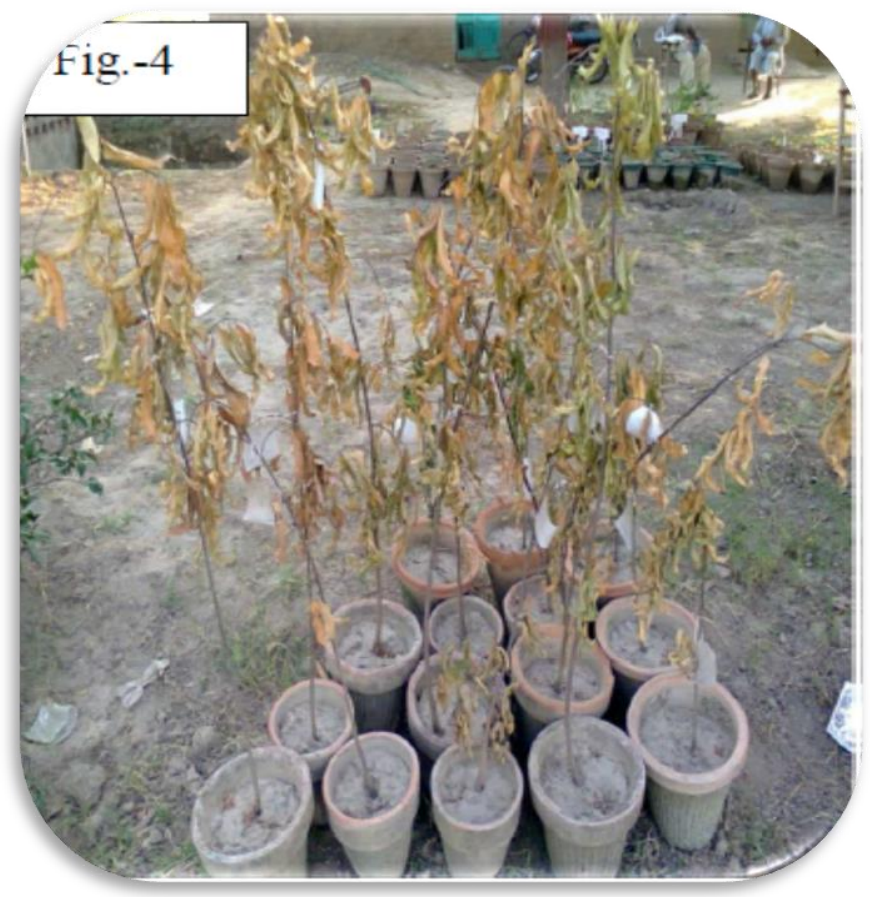

Figure 4. Artificially inoculated plants of P. longifolia representing severe leaf necrosis 


\section{MATERIALS AND METHODS}

For the isolation and identification of the involved pathogen symptomatic $P$. longifolia leaves were collected from naturally infected plants. These leaves were cut into small pieces $(5 \mathrm{~mm})$ and surface sterilized in $0.25 \%$ sodium hypochlorite solution for $3 \mathrm{~min}$, rinsed 3 times in sterilized water and dried on blotter paper under sterile air flow conditions. These small segments were then transferred into petri plates containing $20 \%$ potato dextrose agar medium and incubated at $25^{\circ} \mathrm{C}$ under a 12 -h light and dark regime. Different fungicides (Antracol, Halonil and Aerosol) was used in vitro to evaluate their effect on colony growth of the fungus following poison food technique (Dhingra and Sinclair,1985). A representative specimen of $N$. sphaerica from P. longifolia was deposited in the Herbarium of First Fungal Culture Bank of Pakistan (FCBP), Institute of Agricultural Sciences (IAGS), Punjab University (PU) Lahore, on living leaves of $A$. philoxeroides with Accession No. of FCBP\#1209.

To confirm the pathogenecity of obtained isolate, $N$. sphaerica was multiplied on potato dextrose agar medium at $25^{\circ} \mathrm{C}$ under a cool-white florescent diurnal light with a $12 \mathrm{~h}$ dark and light cycle. After 10 days, conidia were harvested by applying sterilized deionized water (containing $0.01 \%$ Tween 20) and gently scraping the culture surface with a microscopic glass slide. The conidial suspension was filtered through a $0.5 \mathrm{~mm} 2$ pore strainer to remove mycelia debris (Akhtar et al., 2011; 2012). The resulting spore suspension was adjusted to 106 conidia per ml using a 59. haemocytometer (Farr and Rossman, 2010). Koch's postulates were fulfilled using the whole plant assay. For this purpose, one month old, 15 plants of $P$. longifolia were sprayed with the prepared conidial suspension (106 conidia /ml) and were kept in nethouse under natural conditions (average maximum $45^{\circ} \mathrm{C}$, minimum $41^{\circ} \mathrm{C}$ temperature, and relative humidity 65\%). A similar set sprayed with distilled water only was included as a negative control. Fungicidal suspensions of different concentrations were prepared by dissolving requisite quantities of each fungicide in warm PDA. About $15 \mathrm{ml}$ of sterilized medium was poured in each $9 \mathrm{~cm}$ sterilized Petri dish. After solidification, the plates were inoculated by placing $5 \mathrm{~mm}$ discs of 3 days old PDA cultures of the fungus. Three replicated plates were used for each concentration of every fungicide. Three replicated PDA plates received no fungicides was served as control. The inoculated plates were incubated at $28^{\circ} \mathrm{C}$ and data on the radial colony diameters was recorded after 4-5 days of incubation when the growth of the control plates completely covered the plate. Inhibition of radial growth was computed based on colony diameters on control plate using the following formula. (Sunder et al.,1995).

$$
\% \text { Inhibition }=\frac{\mathrm{X}-\mathrm{Y}}{\mathrm{X}} \times 100
$$

Where,

$\mathrm{X}=$ Growth of control plate

$Y=$ Growth of fungicide treated plate.

The collected data was analyzed statistically by employing the Fisher analysis of variance technique (Steel et al., 1997) and treatment means will be compared by using Least Significance Difference (LSD) test at $5 \%$ probability level.

\section{RESULTS AND DISCUSSIONS}

Initially colonies of fungus were white, then changing to brown to black due to the onset and abundance of sporulation. Conidiogenous cells on superficial hyphae, lateral or terminal, swollen, ampulliform, 8$11 \mu \mathrm{m}$ in diameter, hyaline, with a single conidium at the attenuated apex. Conidia were black, single celled, globose $(14-18 \mu \mathrm{m})$, borne on a hyaline vesicle at the isolated pathogen coincided with the description of Nigrospora sphaerica (Ellis, 1971) therefore, the pathogen was identified as $N$. sphaerica. Disease symptoms were started on inoculated plants as drying of leaves from margin after 3 weeks of inoculation followed by complete leaf necrosis 20 days after inoculation (Figure 4) and N. sphaerica was reisolated from infected leaves. However, plants sprayed with distilled water (negative control) remained green till the end of experiment. Nigrospora sphaerica is a cosmopolitan species and has been reported as a leaf blight/spot pathogen on several hosts worldwide including mulathi (Glycyrrhiza glabra) in India (Verma and Gupta, 2008), Cucuma (Cucuma wenyujin) in China (Zhang et al., 2011), Chinese wisteria (Wisteria sinensis) in Turkey. This is the first report of $N$. sphaerica as a causal pathogen of leaf and stem blight of $P$. longifolia in Pakistan. Identification of $N$. sphaerica as causal agent of $P$. longifolia leaf blight in Pakistan will be helpful to suggest effective control measures to manage this disease in future. 
Effect of different fungicides (at concentration of $500 \mathbf{~ p p m}$ ) on mycelia growth of $N$. sphaerica after third week: All fungicides with concentration of 500 ppm inhibit the fungal growth of Nigrospora sphaerica presented in Figure 5 There were three fungicides named Antracol, Halonil, and Aerosol were evaluated against Nigrospora sphaerica .. There was variation in effectiveness among test fungicides in accordance of reducing the fungal growth considerably. It was noted that Halonil was statistically significant in reducing growth of fungus Nigrospora sphaerica and showed about $3.0 \mathrm{~cm}$ colony diameters, followed by Antracol with $4.9 \mathrm{~cm}$, at concentration of $500 \mathrm{ppm}$. Aerosol at concentration of $500 \mathrm{ppm}$ was statistically least significant with $5.7 \mathrm{~cm}$.

Mycelial Growth

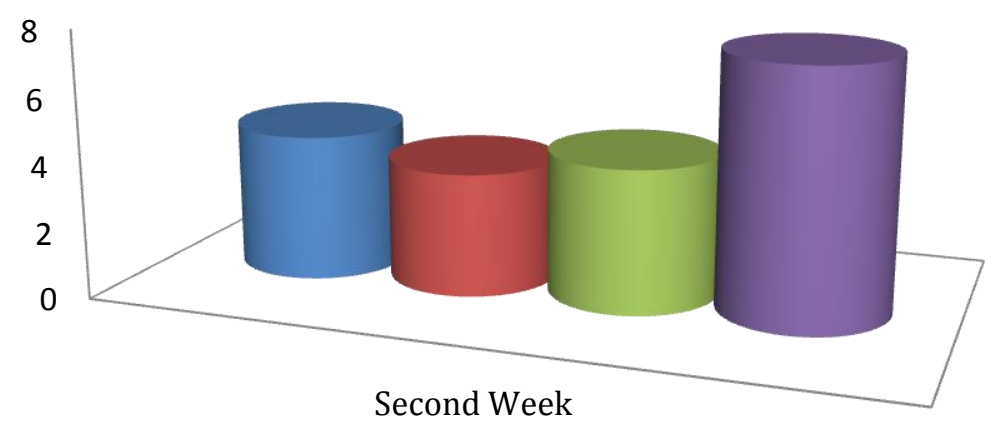

Treatments

- Antracol $\square$ Halonil $\quad$ Aerosol $\quad$ Control

Figure 5. Effect of different fungicides (at concentration of $500 \mathrm{ppm}$ ) on mycelia growth of $N$. sphaerica after second week. All fungicides with concentration of $1000 \mathrm{ppm}$ inhibited growth considerably. It was noted that Halonil was the fungal growth of Nigrospora sphaerica presented in Figure 6. There were three fungicides named Antracol, Halonil, and Aerosol were evaluated against Nigrospora statistically significant in reducing growth of fungus Nigrospora sphaerica and showed about $1.7 \mathrm{~cm}$ colony sphaerica. There was variation in effectiveness among test fungicides in accordance of reducing the fungal diameters, followed by Antracol with $4.9 \mathrm{~cm}$, at concentration of $1000 \mathrm{ppm}$. Aerosol at concentration of $1000 \mathrm{ppm}$ was statistically least significant with $5.4 \mathrm{~cm}$.

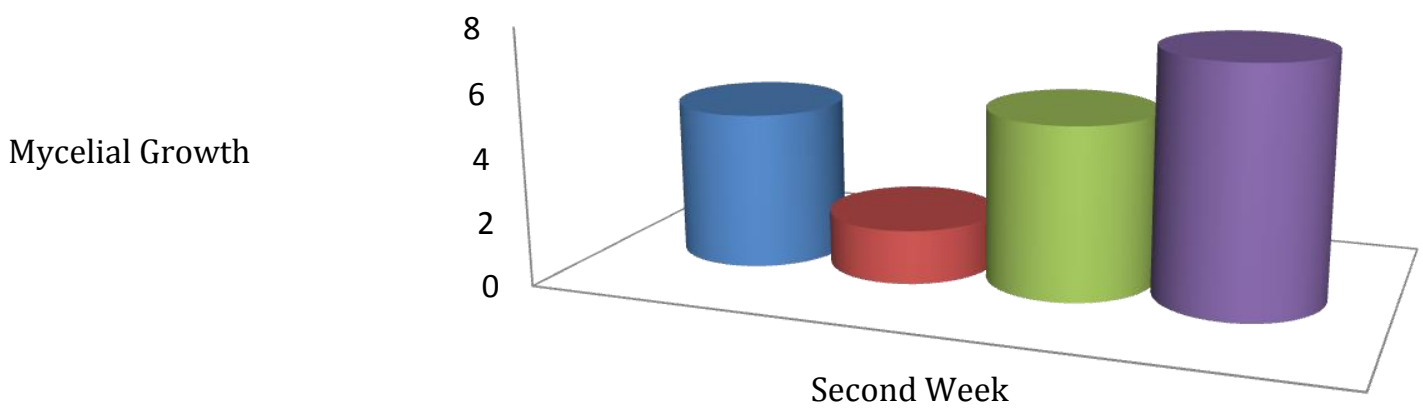

Treatments

$$
\square \text { Antracol } \square \text { Halonil } \square \text { Aerosol } \quad \text { Control }
$$

Figure 6. Effect of different fungicides (at concentration of $1000 \mathrm{ppm}$ ) on mycelia growth of $N$. sphaerica after second week. 
Three different fungicides (Antracol, Halonil and Aerosol) were used in in vitro to evaluate their effect on colony growth of the fungus following poison food technique. Two concentrations viz: 500 ppm 1000 ppm was prepared for each fungicide. Three replications were made for each treatment. Out of three fungicides used, Halonil found to be most effective fungicide by reducing the mycelia growth of Nigrospora sphaerica by $80 \%$ and followed by Antracol and Aerosil by 47\%, 40\% respectively.

\section{REFERENCES}

Akhtar, K. P., N. Sarwar and I.U. Haq, 2012. Nimbya alternantherae reported for the first time to cause leaf and stem necrosis of Alternanthera philoxeroides (alligator weed) in Pakistan. Trop. Pl. Pathol., 37: 428-430.

Akhtar, K.P., N. Sarwar, M. Y. Saleem and M. Asghar, 2011. Convolvulus arvensis, a new host for Alternaria solani causing early blight of Solanum lycopersicum in Pakistan. Aust. Pl. Dis. Notes., 6: 84-86.

Chen, C.Y., F.R. Chang, Y.C. Shih, T. J. Hsieh, Y.C. Chia and H.Y. Tseng, 2000. Cytotoxic constituents of Polyalthia longifolia var. pendula. J. Nat. Prod., 63:1475-1478.

Dhingra, O.D and J.B. Sinclair. 1985. Basic Plant Pathology Methods. CRC Press, Inc., Florida, USA, 355pp.

Ellis, M.B, 1971 'Dematiacceous Hyphomycetes'. CMI: Kew, UK.

Farr, D.F and A.Y. Rossman, 2010. Fungal database, systematic mycology and microbiology laboratory, ARS, USDA. Retrieved July 15, 2010, from http:// nt.ars-grin.gov/fungal database.
Haq, I.U., S. A. Khan \& M. Shoib, M. Iqbal (2014) First record of Polyalthia Longifolia Leaf Blight caused by Nigrospora sphaerica in Pakistan and its chemical management. In $8^{\text {th }}$ international conference on "agriculture, food security and climate change" Sep,2014 University of Poocnh Rawalakot

Mitra, D., D.D. Sharma,N.P. Balakrishnan, R.R. Rao and P.K. Hajara, 1993. Flora of India (RanunculaceaeBarclayaceae). Bot. Sur. Ind., 1:202-203.

Nair, R., V. Shukla and S. Chanda, 2007. Assessment of Polyalthia longifolia var. pendula for hypoglycemic and antihyperglycemic activity. J. Clin. Dia. Res. 3:116-121.

Steel RGD, J.H Torrie, D.A Dicky (1997) Principles and procedures of statistics-A Biometrical Approach. $3^{\text {rd }}$ edn. McGraw Hill Book International Co, Singapore.

Sundar, A.R., N.D. Das and D. Krishnaveni. 1995. In-vitro Antagonism of Trichoderma spp. Against two fungal pathogens of castor. India J. Plant Protec. 23(2):152-155. The American Phytophological Society, 28-31.

Verma, O.P. and R.B.L.Gupta, 2008. A new host for Nigrospora sphaerica causing leaf spots on Glycyrrhiza glabra. Pl. Pathol., 57: 782.

Warrier, P.K., V.P.K. Nambiar and C. Ramankutty, 2002. Indian medicinal plants. IV. Orient Blackswan, India., Pp 330.

Zhang, L.X., J.H. Song and G.J. Tan, 2011. First report of leaf blight caused by Nigrospora sphaerica on curcuma in China. Pl. Dis., 95: 190-194. 